\title{
Factors affecting psychological problems in primary caregivers of People with Multiple Sclerosis: A qualitative study
}

\author{
Bita Sadeghi', Fatemeh Estebsari', Maryam Rassouli², Abbas Ebadi ${ }^{3}$
}

'Department of Community Health Nursing, School of Nursing and Midwifery, Shahid Beheshti University of Medical Sciences, Tehran, IR Iran.
${ }^{2}$ Cancer Research Center, Shahid Beheshti University of Medical Sciences, Tehran, IR Iran.
${ }^{3}$ Behavioral Sciences Research Center, Life Style Institute, Nursing Faculty, Baqiyatallah University of Medical Sciences, Tehran, IR Iran
Corresponding author: Fatemeh Estebsari (E-mail: fatemeestebsari@yahoo.com)
(Submitted: 15 August 2020 - Revised version received: 01 September 2020 - Accepted: 27 October 2020 - Published online: 26 December 2020)

\begin{abstract}
Objectives: The present research aimed to explore factors affecting psychological problems among primary caregivers of individuals with multiple sclerosis (PCIMS).

Methods: The present qualitative research employed a content analysis approach and was conducted in Isfahan, Iran in 2018-19. The participants were selected through purposive sampling method. Semi-structured interviews were conducted to explore psychological problems involved in providing care to MS patients and the factors affecting them with 8 patients, 10 caregivers and 3 healthcare providers. Conventional content analysis was used to analyze the data.

Results: The acquired data were put in four main categories: (i) "isolation and loneliness," (ii) "caregiver's concerns," (iii) "frustration and hopelessness," and (iv) "disruption in the family foundation," each with certain subcategories.

Conclusion: The present results can be helpful to manage psychological disorders and the underlying factors of PCIMS. Thus, healthcare providers and policymakers should consider these areas and make special attempts to improve the performance and conditions of these caregivers to maximize the quality of care provided.

Keywords: multiple scleroses, primary caregiver, family caregiver, qualitative research, psychological burden.
\end{abstract}

\section{Introduction}

Multiple sclerosis (MS) is among the most prevalent progressive chronic neurological diseases that leads to neurodegeneration in adults and about two and a half million people worldwide $^{1}$ and about 60,000 afflicts in Iran. The prevalence rate of this disease in Iran has been 20 times as high as other countries in the region. ${ }^{2}$ In the past, Iran was known as a country with a low prevalence of MS. Yet, recent research has shown that the rate of the disease has been significantly increased, and the maximum prevalence rate of the disease has been reported in Isfahan province ( 80 per 100,000 populations). ${ }^{3}$ Due to its unpredictable nature, this disease can be stressful to all family members. Its occurrence during youth and early adulthood, marked by a critical period of seeking employment and marriage, can add to the psychological burden of this disease. ${ }^{4}$ In the long run, a patient might require primary carer, due to failed daily activities, which is often provided by a family member. Most often, these caregivers are neglected. ${ }^{5,6}$ Caregivers are referred to as hidden patients, who tolerate a great deal of emotional burden in fulfilling their tasks. ${ }^{7}$ Taking care of a patient with a chronic disease creates a lot of tension for the family and caregivers. Caregivers are particularly vulnerable to stress because the patient's biological, social, and psychological needs are often prioritized to their own needs, and they get burned out due to the high loads of pressure and needs. ${ }^{8}$ Taking care of people with MC differs from other chronic diseases, as this disease does not follow a certain trend and is inherently unpredictable. Concerning this disease, the caregiver is unable to precisely predict the occurrence, recurrence, and progression of the disease and even the functional ability of patient during a day. ${ }^{9}$ This instability and unpredictability of needs would add to the caregiving burden of this disease compared to other chronic diseases. ${ }^{10}$ Caregivers suffer from many physical and psychological adverse of the stress involved in caregiving. There is research evidence that the care provided by a spouse or parent at home or in the long run is accompanied by functional limitations and psychological symptoms such as depression in caregivers. ${ }^{11}$ Developments in solving health issues have replaced care-providing institutes with family caregivers. ${ }^{4}$ As the topic of home care has attracted the attention of health professionals in the present century to reduce costs and increase the quality of care services, on the other hand, a vast majority of research has addressed the patient rather than the patient's family or caregivers, though they are faced with many problems in taking care of patients, Therefore, the present research aimed to explore the factors affecting psychological problems of primary caregivers of individuals with multiple sclerosis (PCIMS).

\section{Materials and Methods}

In the present research, conventional content analysis was used to collect and analyze the required data directly based on participants' experiences and perceptions with no assumptions. An inductive process was followed to extract the codes, categories, and subcategories. ${ }^{12,13}$ In this research, which was conducted in Isfahan MS Association in 2018-19, purposive sampling was used to select the participants. MS patients, caregivers who were usually family members and the medical staff including a neurologist, nurse, and psychologist comprised the participants of this research.

The inclusion criteria were willingness to participate. Primary caregivers with at least one year experience of 
caregiving for MS patients, healthcare providers with at least one year of work experience in sections related to MS disease, and patients with at least one year of diagnosis.

According to the above-mentioned inclusion criteria, interviews were held with 32 participants (16 caregivers of MS patient and 10 MS patients aware of caregivers' experience, and 6 healthcare providers with experience of working with MS patients and their families). Table 1 lists the participants' demographic characteristics.

\begin{tabular}{|c|c|c|c|c|c|c|c|}
\hline ID code & Age & Sex & Marital status & Job & Education & $\begin{array}{c}\text { Relation with } \\
\text { individual with MS }\end{array}$ & $\begin{array}{l}\text { Years of } \\
\text { disease }\end{array}$ \\
\hline C1 & 49 & Female & Married & Housekeeper & Primary & Mother & 6 \\
\hline C2 & 38 & Male & Married & Employee & BS & Husband & 7 \\
\hline C3 & 50 & Male & Married & Unemployed & Primary & Husband & 5 \\
\hline C4 & 58 & Female & widow & Unemployed & Primary & Mother & 15 \\
\hline C5 & 46 & Male & Married & Employee & Diploma & Wife & 4 \\
\hline C6 & 28 & Female & Married & Housekeeper & Diploma & Wife & 8 \\
\hline $\mathrm{C} 7$ & 38 & Female & Married & Housekeeper & Diploma & Wife & 8 \\
\hline C8 & 61 & Female & widow & Employee & BS & Mother & 5 \\
\hline C9 & 38 & Male & Married & Housekeeper & BS & wife & 4 \\
\hline $\mathrm{C} 10$ & 33 & Female & Married & Unemployed & Primary & Daughter & 10 \\
\hline C11 & 41 & Male & Married & Employee & MS & Husband & 6 \\
\hline $\mathrm{C} 12$ & 22 & Female & single & Employee & BS & Daughter & 3 \\
\hline $\mathrm{C} 13$ & 48 & Female & divorced & Employee & BS & Mother & 5 \\
\hline $\mathrm{C} 14$ & 45 & Female & Married & Employee & BS & wife & 4 \\
\hline C15 & 52 & Male & Married & retired & Diploma & father & 17 \\
\hline $\mathrm{C} 16$ & 57 & Female & Married & Housekeeper & Primary & Mother & 9 \\
\hline P1 & 44 & Female & Married & Housekeeper & Primary & -- & 5 \\
\hline P2 & 43 & Female & divorced & Unemployed & Primary & -- & 6 \\
\hline P3 & 32 & Male & Married & Unemployed & BS & -- & 4 \\
\hline P4 & 40 & Female & Married & Housekeeper & BS & -- & 5 \\
\hline P5 & 30 & Female & Married & Housekeeper & BS & -- & 6 \\
\hline P6 & 40 & Female & divorced & Unemployed & BS & -- & 5 \\
\hline P7 & 42 & Male & Married & Employee & Diploma & -- & 8 \\
\hline P8 & 22 & Female & Single & Student & BS student & -- & 3 \\
\hline P9 & 25 & Female & Single & Student & BS student & -- & 5 \\
\hline P10 & 33 & Male & Married & Unemployed & MS & -- & 10 \\
\hline $\mathrm{H} 1$ & 38 & Female & -- & nurse & BS & -- & -- \\
\hline $\mathrm{H} 2$ & 26 & Female & -- & nurse & BS & -- & -- \\
\hline $\mathrm{H} 3$ & 30 & Female & -- & nurse & BS & -- & -- \\
\hline $\mathrm{H} 4$ & 36 & Male & -- & Physiotherapist & BS & -- & -- \\
\hline $\mathrm{H} 5$ & 52 & Male & -- & neurologist & specialist & -- & -- \\
\hline $\mathrm{H} 6$ & 41 & Male & -- & Psychologist & $\mathrm{PhD}$ & -- & -- \\
\hline
\end{tabular}

ID code (c: caregiver, p: patient, h: healthcare provider). 


\section{Data Collection}

The research data were collected via in-depth semi-structured interviews from September 2018 to August 2019. Each interview started with open questions regarding the experience of caregiving and gradually followed by more detailed questions about the psychological problems caused by caregiving. The data collection continued with patients and medical staff dealing with these caregivers. At first, they were asked to share their experience of taking care of MS patients. Examples of open questions: "Please talk about the psychological problems you had with caregiving", "What factors do you consider to be involved in creating these problems?" When the participants had problems describing their experiences or when the interview needed to be more specialized, follow-up questions were asked for clarification: "Can you explain more?," "What do you think about this?," "Can you provide an example?” All the interviews were held in a calm and private place (in MS association, participants' home, or workplace). Each interview, depending on participants' physical and psychological conditions, took between 30 and 80 minutes. All interviews were tape-recorded. Non-verbal behaviors were noted as field notes by the interviewer. They were also used as complementary data and were used for trustworthiness. The sample size was based on the data saturation. Thus, selection of eligible cases continued until adequate data were collected (data saturation phenomenon). ${ }^{14}$

In this research, data saturation occurred after conducting 21 interviews; then, the list of codes was merged and categories were extracted.

\section{Data Analysis}

The data collected in this research were analyzed through conventional content analysis as a systematic data coding and categorizing method. ${ }^{15}$ In this method, the researchers immerse themselves in the data to allow new insights to emerge. ${ }^{16}$ At the same time of data collection, data analysis began too. The interviews were transcribed in Persian and analyzed by the first author. Initially, the tape-recorded interviews were transcribed word by word. Before the coding process, the interviews were read several times by the researcher to get a general sense of the text. Then, the transcribed interviews were reviewed line by line and the main words, phrases, and sentences were identified as meaning units. The main ideas were extracted from them and they took the title of the code. Afterwards, the different codes formed their own subcategories based on their similarities and differences. The subcategories were also compared and those who were similar in terms of features and content merged to form the main categories. Peer check, member check were used to achieve a consensus in coding. Instances of data analysis are included in Table 2.

\section{Rigor}

According to Lincoln and Guba, four criteria are essential for trustworthiness. These include: credibility, dependability, transferability, and conformability. ${ }^{17}$ To increase credibility, prolonged engagement with data and emerging codes and categories was followed (here, engagement with data for more than 11 months) as well as peer checking and member checking. Several sessions were held by the researcher with the participants to delve into their experiences in depth. Moreover, each participant was asked for feedback on the codes and their interpretation. Supplementary comments were collected and essential changes were made. Peer checking was one way to make sure of the dependability and confirmability in research. It was held through weekly meetings between the second and third authors, and two other PhD candidates of Nursing. All research procedures were checked including codes and categories.

Conformability refers to the objectivity and implies that the data accurately represent the information that the participants provided and the interpretation of those data are not invented by the researcher. ${ }^{18}$ Furthermore, trustworthiness includes the question of transferability, which refers to the extent to which the findings can be transferred to other settings or groups. ${ }^{18}$ It was attempted in the present research to include rich quotes from the participants that form the main categories, in order to increase conformability. To make sure of the transferability, the data collection and analysis procedure was described comprehensively.

\section{Ethical considerations}

In this research, all participants were informed before the interview that their participation is fully voluntary. They could withdraw from the research without any conditions, whenever they wanted. Having signed a letter of informed consent, the participants were ensured of the confidentiality of the information they provided. Each participant was interviewed only once. The purpose and significance of study and the research protocol were explained to the participants. Their voice was recorded as they consented to. This research was part of a $\mathrm{PhD}$ dissertation approved by the Research Ethics Committee of SBMU (IR.SBMU.PHNM.1397.53).

\section{Results}

Four main categories were extracted and are shown along with their subcategories in Table 3.

\begin{tabular}{|c|c|c|c|}
\hline Meaning unit & Code & Sub-category & Category \\
\hline $\begin{array}{l}\text { As far as I can } \\
\text { stand on my feet, } \\
\text { I will take care } \\
\text { of my daughter. } \\
\text { But I am worried } \\
\text { about the } \\
\text { upcoming years, } \\
\text { when I lose } \\
\text { my abilities, if } \\
\text { my daughter } \\
\text { cripples, who } \\
\text { will take care of } \\
\text { her? }\end{array}$ & $\begin{array}{l}\text { Concerns } \\
\text { about the } \\
\text { patient's } \\
\text { disability }\end{array}$ & $\begin{array}{l}\text { Physical } \\
\text { concerns }\end{array}$ & $\begin{array}{l}\text { Caregiver's } \\
\text { stresses and } \\
\text { concerns }\end{array}$ \\
\hline $\begin{array}{l}\text { When my } \\
\text { patient's } \\
\text { symptoms } \\
\text { return or a new } \\
\text { problem arises, } \\
\text { I feel there is } \\
\text { nothing I can do } \\
\text { to help her. }\end{array}$ & $\begin{array}{l}\text { Inability } \\
\text { to control } \\
\text { conditions }\end{array}$ & $\begin{array}{l}\text { Feeling } \\
\text { incompetent }\end{array}$ & $\begin{array}{l}\text { frustration and } \\
\text { hopelessness }\end{array}$ \\
\hline
\end{tabular}




\begin{tabular}{ll}
\hline Table 3. Categories and subcategories extracted from the data. \\
\hline Subcategory & Category \\
\hline $\begin{array}{l}\text { Unwillingness and lack of motivation } \\
\text { Sense of pity }\end{array}$ & Isolation and loneliness \\
Patient's low self-confidence & \\
Physical concerns & \\
Psychological concerns & Caregiver's stresses and \\
& concerns \\
Social concerns & \\
$\begin{array}{l}\text { Feeling incompetent } \\
\text { Lack of recovery in the disease's course }\end{array}$ & Frustration and \\
& hopelessness \\
Lack of acceptance of the disease & \\
inadequate knowledge of disease's nature & \\
$\begin{array}{l}\text { Conflict in interactions } \\
\text { Reduced emotional and sexual relations }\end{array}$ & $\begin{array}{l}\text { Disruption in the family } \\
\text { foundation }\end{array}$ \\
$\begin{array}{l}\text { Pessimism toward spouse } \\
\text { Continue married life as a pity }\end{array}$ & \\
\hline
\end{tabular}

\section{Isolation and Loneliness}

Caregivers, due to unwillingness and lack of motivation, freedom from other's pity for the patient and patient's low self-confidence, began to reduce or stop communication with others. Such isolation and loneliness adversely affected the caregiver's psychology.

\section{Unwillingness and Lack of Motivation}

The unfavorable psychological state of the patient and the caregiver made them reluctant to social interactions and reduced social relations and activities.

"I can't take my son home alone for a moment now," said one of the participating caregivers.

With this respect, a participating caregiver stated: "Now I cannot even leave my son alone for a moment at home. If I want to go to my brother's or my sister's house and come back, my mind is constantly on him. It's like my heart is dead and don't feel like talking to anyone. What good is it if I go somewhere and sit in a quiet corner and think about everything?"

\section{Sense of Pity on the Patient}

The participants believed that when a patient receives excessive attention, she/he feels pity. To get rid of this pity, the caregiver and the patient would use methods such as concealment of the disease and keeping a social distance.

Concerning this, a participant patient quoted: "People's excessive attention would convey a bad feeling to me. They keep asking me: How are you? Is it better? Even when some of them see me, they keep whispering Thank God I am not so! We think that if we see less people, we will be less bothered" (P4: female).

\section{Patient's Low Self-Confidence}

According to the present research, there are certain factors that can reduce patient's self-confidence. To compensate for this defect, the patient and caregiver might reduce social relations or even cease them entirely.
A participating caregiver stated: "My wife, due to her walking problems, prefers to stay home and not to go out. At home, she uses a wheelchair easily but she avoids going out with the fear of others staring at her on the wheelchair. When she doesn't come with me, I also don't like to go to family parties and ceremonies alone" (C3: male).

\section{Caregiver's Stresses and Concerns}

This category is made up of the caregiver's physical concerns, social concerns, and family concerns subcategories, as introduced in the following:

\section{Caregiver's Physical Concerns}

These concerns deal more with the patient's possible future physical problems, such as fear of the patient's disability, and his/her own probable physical problems, which in both cases have a negative psychological impact on the caregiver

As an instance, one participating caregiver stated: "As long as I can stand on my feet, I will take care of my daughter. But I am worried about the upcoming years, when I lose my abilities, if my daughter cripples, who will take care of her??" (C1: female).

\section{Caregiver's Social Concerns}

Some caregivers were concerned about the future of their patients. These concerns were more about the patient's career, income, and marriage which would eventually affect the caregiver's psychology negatively.

With this regard, a participating caregiver mentioned: "Before my daughter was sick, she used to work and had a good income. She was busy with her job. Now that she is sick, she has to stay home and I keep wondering what's going to happen to her. Not only her job, but also her chances of marriage worry me. Can she ever marry?" (C8: female).

\section{Caregiver's Family Concerns}

The majority of participants in this research believed that this disease affected their mood tremendously and would get on the patient's nerves in many cases. A concern of the caregivers was the patient's constant moody behavior toward other family members which could gradually disrupt effective communication with family members and fade away the existing emotions they had for each other.

As an example, a participating caregiver maintained: "My daughter has become quick-tempered due to her illness. She gets easily offended and insists that we should not come to her house any longer. She keeps shouting at her child and arguing with her husband. I'm afraid soon her husband's patience will end and leave her. I'm much worried" (C1: female).

\section{Frustration and Hopelessness}

As some caregivers stated, while they take care of an MS patient, they gradually feel tired and frustrated and move little by little to disappointment. This category consists of such subcategories as Feeling incompetent, lack of recovery in the disease's course, lack of acceptance of the disease, and inadequate knowledge of disease's nature.

\section{Feeling Incompetent}

When the symptoms of disease recurred, the caregivers felt unable to control conditions; thus, their sense of control, competence, and identity was disrupted. 
With this regard, a participating caregiver commented: "When my patient's symptoms return or a new problem arises, I feel there is nothing I can do to help her. I feel I am a different person" (C9: male).

\section{Lack of Recovery in the Disease's Course}

As the data analysis revealed, caregivers and patients experienced many challenges during the disease. While tolerating the disease problems and hardship, in the face of no improvement in patient's physical and psychological conditions, the patient and the caregiver both find themselves in a submissive state and give in to the disease and its adverse effects.

As an instance, a caregiver commented: "When I see the time passes, yet the patient does not get any better, I lose hope and see no sense in seeing different doctors. Sometimes, my poor son says let's stop buying expensive ampoules. It's too late and I only wish to die calmly and proudly" (C4: female).

\section{Lack of Acceptance of Disease}

As the data analysis showed, patients and caregivers who did not manage to accept their condition experienced more problems with the disease. They had a lower self-confidence. In the face of the disease, they showed less resistance and sooner felt exhausted and frustrated.

Concerning this, a participating caregiver said: "After so long a time, my husband hasn't accepted his disease. He tends to hide his disease, as he is somehow proud. He says there is nothing. He doesn't help to treat himself. Even for visiting doctor and Taking his medication, I have to insist every time to be satisfied. Whenever the symptoms recur, he gets nervous and complains. He always complains why it all happened to him. It makes everything harder for me. It's really hard for me. I am very upset by this situation" (C7: female).

\section{Inadequate Knowledge of Disease's Nature}

Not knowing the reliable and accurate information sources and consequently not knowing the disease' nature led patients and caregivers to seek information at unreliable databases. Or they might easily yield to incorrect medical advice by unreliable sources and act accordingly. This can impose high costs for the act of caregiving. Besides, it can add to the symptoms of disease and finally leave the patient frustrated when no sign of improvement is observed.

As an example, a patient quoted: "My wife found someone via the net who claimed to be an herbal medicine specialist. $\mathrm{He}$ claimed to find new treatments for MS. When we paid him, he sent over some home-made tablets which left me hospitalized for a week" (P3: male).

\section{Disruption in the Family Foundation}

As the data analysis revealed, disruption in the family foundation was another main category extracted from the present research. Damages to family caused by decrease in the patient's/ caregiver's tolerance threshold and their introspection and the disintegration of coherence, all attested to the vulnerability of family with an MS patient. This class was mostly in cases where the caregiver was the patient's spouse. The underlying factors as the subcategories leading to such problems were: conflict in interactions, reduced emotional and sexual relations (of couples), pessimism toward the spouse, and continue married life as a pity. These subcategories will be introduced below.

\section{Conflict in Interactions}

As the research data showed, one reason for the creation of familial and marital problems was conflict in interactions among family members, and it is dramatically affected by sudden changes to patient's moods and their unreasonable anger.

As an instance, a participant described: "Unfortunately, many MS patients develop moody behavior and thus misbehave on different conditions which manifests itself mostly in the form of anger and aggression. Moreover, many families and caregivers are not aware that this moodiness are due to the disease. So, they react inappropriately and get into conflict in interactions" (H2: female).

\section{Reduced Emotional and Sexual Relations of Couple}

As the data revealed, this disease disrupts the sexual relationship of couples. Occasionally, besides the patient, the caregiver also has sexual problems. Spouses who act as the caregiver stated that such sexual problems usually result from the psychological burden of the caregiving and the consequent mental concerns, and there existed no physiological defect.

As an instance, a caregiver stated: "My wife is totally frigid. My sexual desire has decreased too. It must be due to too much stress and tension" (C9: male).

As the participants commented, this problem would cause emotional coldness in patient-caregiver relations and it was unpleasant to the caregiver.

Here is part of a patient's comment: "I really feel I am not able to meet my husband's sexual desire. We are no longer warm and friendly. We look more like home mates. My husband grumble sometimes. I don't expect him to understand me. As a man, how long is he going to tolerate it?" (P2: female).

\section{Pessimism Toward the Spouse}

As the data revealed, some patients got pessimistic toward their spouse and did not feel secure in life anymore. Thus, they misbehaved toward their caregiver. Often, the patient's spouse reacts inappropriately which would gradually disrupt emotional relations. This disruption can in turn have such consequences as marital and social problems and even divorce.

Here is a comment made by a participating caregiver: "One factor that turns us away from each other is that my wife thinks now that she has MS, I intend to marry someone else. She distrusts me and makes me very angry, she keeps being sarcastic and keeps checking my telephone. That's why we have argued so often" (C3: male).

\section{Continuing Married Life Due to Pity}

In some cases, the patient believed that his spouse continued their married life with no true love and only due to pity.

As an instance, a patient commented: "I feel that my wife only continues our life for God's sake. She pities me. Only her religious beliefs make her stay with me. Otherwise, she no longer feels happy in this life. I even told her I don't need her sympathy. I asked her to leave me and continue her own life. I don't know why she insists that I think everything is as ever before. When i says this, she gets upset. This thought that comes to mind bothers me a lot. Actually, our love has turned artificial and forced. It's as if we are just pretending" (P3: male). 


\section{Discussions}

The present research showed that different factors are involved in creating caregivers' psychological problems in the case of MS patients. According to the participants' experiences, four categories were involved in creating caregivers' psychological problems. These included "isolation and loneliness," "caregiver's concerns," "frustration and hopelessness," and "disruption in the family foundation." In the qualitative research, Shapiro et al. had 4 groups with a focus on 15 MS patients and their caregivers to explore caregivers' misbehaviors toward the patients. They concluded that a key reason why caregivers misbehaved toward patients was their social isolation. ${ }^{19}$ Others' sense of pity on MS patients showed to be an effective factor in patient's social isolation followed by caregiver's isolation. As the participants stated, patients disliked being pitied. To avoid a sense of pity, they attempted to hide their disease and communicate less with others. To this aim, caregivers also had to cut down on their social relations so as to keep others in the dark about the disease. Social isolation has been also discussed in a body of research on MS patients and their caregivers. ${ }^{20-22}$ Such subcategories as "sense of pity on patients" have been in common with the present research. ${ }^{21,22}$ Similarly, in a qualitative study conducted by Bogosin et al., the aim was to explore the experience of 15 caregivers of MS patients. In this research, one reason the caregivers brought for their isolation was that wherever the patients went, they thought they were the center of attention; they were pitied by others, and thought they were incapable of doing anything. They might actually be cognitively mistaken as this might not be as others truly think about them. Thus, they try to hide their disease in an attempt to get along with the psychological burden of pity and similar to other related studies, ${ }^{22}$ they might end in social isolation and the same can go for their caregivers. ${ }^{23}$

Caregiver's concerns were another main category in the present research and showed to be an effective factor in caregivers' psychological problems. In this research, the participants maintained that their physical and social concerns created a psychological burden for them. With this regard, Mutch in another study mentioned "caregiver's concerns" as a category, as he found that caregivers of MS patients were concerned about their patient's prospective life and his/her physical and social conditions. ${ }^{24}$

In the present research, the participating caregivers also maintained that their family concerns were more about disrupting dynamic relations among family members. With this concern, Kouzoupis indicated that MS patients influenced all family members and this influence can differ across members. That is why each member can use a different strategy to cope with the effects of the disease. Such strategies might be in conflict, which can in turn cause more stress for family members and disrupt family dynamics. ${ }^{25}$ Caregivers often worry about their own future, their patient, and their family in general. Concerns about the aggravation of patient's conditions prevailed among caregivers, as this could imply further needs and care burden..$^{24,26,27}$ Many caregivers worry about the loss of their own health which could restrict their ability to take care of their beloved patient. And, it may eventually force them to leave their patients in care centers. ${ }^{9,27}$ Frustration and hopelessness was another category in the present research. It was partly induced by no sign of improvement in patient's conditions. In his research, Masoudi found that continuous stress and no sign of improvement in patient's conditions can frustrate the caregiver and reduce the quality of caregiver's performance and the quality of the care s/he provides. ${ }^{28}$ Another subcategory of this category was inadequate knowledge of the nature of disease. Similar research findings revealed that primary caregivers required the knowledge and awareness of caregiving, so that they could act effectively as a caregiver. This could reduce their distress and burden. The lack of knowledge could negatively affect caregiver's physical, psychological, and social health. ${ }^{29,}{ }^{30}$ In the present research, some participants talked about traditional and cultural beliefs such as medical and nutritional beliefs rooted in their limited awareness of the disease. By implementing these beliefs, they caused more disabilities in the patient and this factor would add to the caregiver's pressure. Some other related studies discussed the medical and nutritional beliefs of MS patients' caregivers (such as the benefits of consuming linseed oil, aromatherapy or bee therapy). It has also been pinpointed that these cases in combination with pharmacology can have adverse effects and can even reduce the effect of medicines. ${ }^{31}$

In the qualitative study by Bogosian et al..$^{24}$, some participants stated that they had met MS patients before; this background might have meant inability to control the disease and its symptoms to them. ${ }^{23}$ And according to this belief, the person has used strategies to avoid and hide the disease to deal with the psychological burden of the disease. Such perceptions of the disease can tremendously affect the results, adaptive strategies, and self-management such as accepting treatments and medical priorities. ${ }^{32}$

Disruption in the family foundation was found to be another category in this research. It resulted from contact in interactions, reduced emotional and sexual relations of the couples, pessimism toward the spouse, and continuing life due to pity. A body of related literature on MS showed that this disease can cause many marital problems and can disrupt the relations of the couples..$^{23,33,34}$ In the present research, one reason for the occurrence of marital problems was patient's sexual problems followed by the caregiver's unmet emotional needs. In another study, Rollero ${ }^{35}$ drew attention to the theme of "changes in the couple" and admitted that PCIMS often suffered from sexual problems and their needs were left unmet. Participants in this research stated that sex mattered to them but for many reasons including patient's constant fatigue, this need was left unmet. This had disrupted their marital relations. ${ }^{35}$ The same was acknowledged by the participants in the qualitative research by Courts et al. who complained about problems in sexual relations, and they mentioned it as a factor involved in changing their communication with the spouse. ${ }^{31}$

In their review study, Schulz et al. explored the psychological and physical effects of caregiving on primary caregivers and concluded that sexual problem was a key factor involved in primary caregivers' stress and depression and low mental health. ${ }^{36}$ One factor found among reasons for creating contact in family interactions was patient's distrust in the caregiver and patient's changing mood and continuous aggression. In some qualitative research, Courts et al. ${ }^{31}$ explored the experiences of those with an MS afflict spouse. Some of the participants maintained that MS could cause aggression and marital problems for the couples and could even lead to divorce. Yet, in the same study, some of the other participants, contrary to our study, stated that with the diagnosis of MS, their marital relationship has become stronger. ${ }^{31}$ In this regard, Mutch in 
its qualitative study (content analysis) (2010) on the spouses of people with MS, about their experience of caring for these patients, according to the participants' statements concluded that after the disease was diagnosed, their marital relations were further strengthened. Such strength was perceived by some participants as a motivation for continuing the caregiving tasks and adapting to the caregiving burden. ${ }^{24}$

Another finding of the present research was pessimism toward the spouse which could disrupt marital relations. The qualitative research by Courts et al., conducted on 12 spouses of people with MS, some acknowledged that their spouses thought they would leave them soon. However, the patients did not share these negative thoughts with the spouses. Accordingly, a participant in this research mentioned that when he got to know what his wife thought, he began to support her cognitively and ensured her that she was wrong. ${ }^{31}$

In the content analysis by Bogosian et al., some participants maintained that patient's mood swings and aggression often disrupts the relationship between the couples and it causes them to quarrel. ${ }^{23}$ Other related body of literature also showed that the caregivers should not only care about the physical symptoms of MS disease but also be aware of the psychological aspects often manifested as moodiness. ${ }^{37}$ This moodiness can impose much distress on the caregiver and can adversely affect her/his quality of life. It can disrupt caregiver's adaptation to the caregiving role and the relevant problems and can even entirely disrupt the patient-caregiver relations. ${ }^{38}$

\section{Conclusion}

The present findings revealed the factors affecting psychological problems of PCIMS. They are all of a great significance and psychological consultation seems to be able to help caregivers in all stages of the disease to solve these problems and be better prepared to act efficiently in taking care of MS patients. As this research is qualitative in type, its findings need to be interpreted carefully. The generalization of results is limited to the scope of the present research and to delve into the different aspects of the problems and challenges these caregivers are faced with, further research is required in different contexts.

\section{Acknowledgments}

The present researcher should like to express gratitude to Isfahan MS Association and the research committee of Shahid Beheshti University of medical sciences. The gratitude is extended to all participants who shared their experience and information with the researchers and took part in this research.

Financial Disclosure: None to declare.

Conflict of Interest: None to declare.

\section{References}

1. Topcu G, Buchanan H, Aubeeluck A, Garip G. Caregiving in multiple sclerosis and quality of life: A meta-synthesis of qualitative research. Psychol Health. 2016;31(6):693-710.

2. Gafari S, Khoshknab MF, Nourozi K, Mohamadi E. Informal caregivers' experiences of caring of multiple sclerosis patients: A qualitative study. Iran J Nursing Midwifery Res. 2017;22(3):243.
3. Izadi S, Nikseresht A, Sharifian M, Sahraian MA, Jahromi AH, Aghighi M, et al. Significant increase in the prevalence of multiple sclerosis in iran in 2011. Iran J Med Sci. 2014;39(2):152.

4. Buhse M. Assessment of caregiver burden in families of persons with multiple sclerosis. J Neurosci Nursing. 2008;40(1):25-31.

5. Navab E, Negarandeh R, Peyrovi H, Navab P. Stigma among I ranian family caregivers of patients with A Izheimer's disease: A hermeneutic study. Nursing Health Sci. 2013;15(2):201-6.

6. Masoudi R, Abedi H, Abedi P, Mohammadianinejad SE. The perspectives of Iranian patients with multiple sclerosis on continuity of care: a qualitative study. J Nursing Res. 2015;23(2):145-52.

7. Galushko M, Golla H, Strupp J, Karbach U, Kaiser C, Ernstmann N, et al. Unmet needs of patients feeling severely affected by multiple sclerosis in Germany: A qualitative study. J Palliative Med. 2014;17(3):274-81.

8. Boyd MA. Psychiatric nursing: Contemporary practice: Lippincott Williams \& Wilkins; 2008.

9. McKeown L, Porter-Armstrong A, Baxter G. Caregivers of people with multiple sclerosis: experiences of support. Multiple Sclerosis J. 2004;10(2):219-30.

10. Figved N, Myhr K-M, Larsen J-P, Aarsland D. Caregiver burden in multiple sclerosis: the impact of neuropsychiatric symptoms. J Neurol Neurosurg Psychiatry. 2007;78(10):1097-102

11. Caputo J, Pavalko EK, Hardy MA. The long-term effects of caregiving on women's health and mortality. J Marriage Family. 2016;78(5):1382-98.

12. Corbin J, Strauss A. Basics of Qualitative Research: Techniques and Procedures for Developing Grounded Theory: SAGE Publications; 2014.

13. Speziale HS, Streubert HJ, Carpenter DR. Qualitative research in nursing: Advancing the humanistic imperative: Lippincott Williams \& Wilkins; 2011.

14. Estebsari F, Taghdisi MH, Mostafaei $D$, Jamshidi E, Latifi M. Determining the factors contributing to quality of life of patients at the last stage of life: a qualitative study. Iran Red Crescent Med J. 2013;15(12).

15. Grbich C. Qualitative data analysis: An introduction: Sage; 2012.

16. Hsieh H-F, Shannon SE. Three approaches to qualitative content analysis. Qual Health Res. 2005;15(9):1277-88.

17. Guba EG. Criteria for assessing the trustworthiness of naturalistic inquiries. Educ Technol Res Dev. 1981;29(2):75-91.

18. Estebsari F, Taghdisi MH, Mostafaei D, Rahimi Z. Elements of healthy death: A thematic analysis. Med J Islamic Republic of Iran. 2017;31:24

19. Shapiro J, Wiglesworth A, Morrison EH. Views on disclosing mistreatment: A focus group study of differences between people with MS and their caregivers. Multiple Sclerosis Related Disorders. 2013;2(2):96-102.

20. Masoudi R, Khayeri F, Rabiei L, Zarea K. A study of stigma among Iranian family caregivers of patients with multiple sclerosis: A descriptive explorative qualitative study. Appl Nursing Res. 2017;34:1-6.

21. Ghafari S, Fallahi-Khoshknab M, Nourozi K, Mohammadi E. Patients' experiences of adapting to multiple sclerosis: A qualitative study. Contemp Nurse. 2015;50(1):36-49.

22. Abolhassani S, Yazdannik A, Taleghani F, Zamani A. Social aspects of multiple sclerosis for Iranian individuals. Disab Rehab. 2015;37(4):319-26.

23. Bogosian A, Moss-Morris R, Yardley L, Dennison L. Experiences of partners of people in the early stages of multiple sclerosis. Multiple Sclerosis J. 2009;15(7):876-84.

24. Mutch K. In sickness and in health: Experience of caring for a spouse with MS. Br J Nursing. 2010;19(4):214-9.

25. Kouzoupis AB, Paparrigopoulos T, Soldatos M, Papadimitriou GN. The family of the multiple sclerosis patient: a psychosocial perspective. Int Rev Psychiatry. 2010;22(1):83-9.

26. Heward K, Molineux M, Gough B. A grounded theory analysis of the occupational impact of caring for a partner who has multiple sclerosis. J Occup Sci. 2006;13(2-3):188-97.

27. Cheung J, Hocking P. The experience of spousal carers of people with multiple sclerosis. Qual Health Res. 2004;14(2):153-66. Epub 2004/02/11.

28. Masoudi R, Abedi HA, Abedi P, Mohammadianinejad SE. Iranian family caregivers' challenges and issues in caring of multiple sclerosis patients: A descriptive explorative qualitative study. Iran J Nursing Midwifery Res. 2014;19(4):416

29. Fukui S. Information needs and the related variables of Japanese family caregivers of terminally ill cancer patients. Nursing Health Sci. 2004;6(1):29-36.

30. Given B, Sherwood PR, Given CW. What knowledge and skills do caregivers need? J Social Work Educ. 2008:44(sup3):115-23.

31. Courts NF, Newton AN, MCNeal LJ. Husbands and wives living with multiple sclerosis. J Neurosci Nursing. 2005:37(1):20,

32. Obiwuru O, Joseph S, Liu L, Palomeque A, Tarlow L, Langer-Gould AM, et al. Perceptions of multiple sclerosis in Hispanic Americans: Need for targeted messaging. Int J MS Care. 2017;19(3):131-39. 
Original

Factors affecting psychological problems in primary caregivers of People with Multiple Sclerosis

33. Eriksson M, Svedlund M. 'The intruder': spouses' narratives about life with a chronically ill partner. J Clin Nursing. 2006;15(3):324-33. Epub 2006/02/10.

34. Boeije HR, Van Doorne-Huiskes A. Fulfilling a sense of duty: how men and women giving care to spouses with multiple sclerosis interpret this role. Community Work Family. 2003;6(3):223-44.

35. Rollero $C$. The experience of men caring for a partner with multiple sclerosis. J Nursing Scholarship. 2016;48(5):482-9.
36. Schulz R, Sherwood PR. Physical and mental health effects of family caregiving. J Social Work Educ. 2008:44(sup3):105-13.

37. Coleman J, Rath L, Carey J. Multiple sclerosis and the role of the MS nurse consultant. Aust Nursing J ANJ, The. 2001;9(3):CU1.

38. Sherman T, Rapport L, Hanks R, Ryan K, Keenan P, Khan O, et al. Predictors of well-being among significant others of persons with multiple sclerosis. Multiple Sclerosis Jo. 2007;13(2):238-49.

This work is licensed under a Creative Commons Attribution-NonCommercial 3.0 Unported License which allows users to read, copy, distribute and make derivative works for non-commercial purposes from the material, as long as the author of the original work is cited properly. 